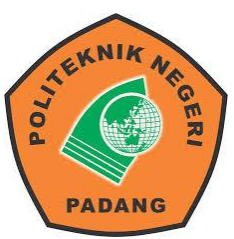

Jurnal Ilmiah Rekayasa Sipil

Available online at : http://ejournal2.pnp.ac.id/index.php/iirs/ Terakreditasi SINTAPeringkat 5

\title{
Analisis Rework Factor pada Pelaksanaan Proyek Gedung di Kota Padang Tahun 2019
}

\author{
${ }^{1)}$ Desmon Hamid, ${ }^{2)}$ Yan Partawijaya, ${ }^{3)}$ Zulfira Mirani, ${ }^{4)}$ Takdir Alamsyah, ${ }^{5)}$ Oktariyan Arla Suhada \\ 1),2),3),4),5) Teknik Sipil Politeknik Negeri Padang \\ Email : desmon_hamid@yahoo.co.uk, yan parta21@yahoo.com, raninawaf@gmail.com, \\ takdir@pnp.ac.id, oktaryan@yahoo.com
}

\begin{abstract}
ABSTRAK
Suatu proyek dikatakan sukses apabila minimal memenuhi empat faktor, antara lain adalah proyek berjalan sesuai jadwal kontrak, mendapatkan keuntungan karena pengeluaran sesuai dengan yang direncanakan, masalah yang terjadi dalam proyek kecil, dan tidak terjadi kecelakaan kerja. Jika teknis yang digunakan kurang baik maka akan berdampak buruk pada kinerja proyek dan dapat menimbulkan kerugian dari segi biaya, mutu, dan waktu. Salah satu kerugian yang ditimbulkan pada pelaksanaan proyek konstruksi disebabkan oleh karena adanya pengerjaan ulang (rework). Dari artikel ini dapat diketahui faktor-faktor yang menjadi penyebab rework dan faktor dominan apa saja yang menjadi penyebab rework pada pelaksanaan proyek gedung di Kota Padang tahun 2019. Instrumen yang digunakan adalah kuesioner yang melibatkan 22 orang responden, terdiri dari 11 perusaaan kontraktor dan masing-masing perusahaan terdapat 2 orang responden yaitu project manager dan site manager. Uji yang dilakukan meliputi uji validitas, reabilitas, korelasi Pearson Product Moment dan analisis deskriptif berdasarkan nilai mean dengan bantuan program Statistical Package for Social Science (SPSS) for Windows version 24.0. Hasik yang didapat teridentifikasi 5 faktor penyebab terjadinya rework yaitu faktor manajerial, faktor metoda pelaksanaan konstruksi, faktor material, faktor sumberdaya manusia dan faktor site conditions. Faktor yang paling dominan penyebab rework adalah faktor manajerial, pada sub faktor kurangnya kerja sama tim (teamwork) sehingga hasil konstruksi tidak sesuai dengan kontrak dengan nilai mean 4.32 dan persentase sebesar $86.64 \%$.
\end{abstract}

Kata Kunci: Rework, Konstruksi Gedung, Penyebab Rework, SPSS

(C) 2019 JurnalllmiahrekayasaSipil

\section{PENDAHULUAN}

Perkembangan proyek konstruksi seiring berjalannya waktu semakin kompleks dan mengalami banyak perubahan baik itu berhubungan dengan teknologi yang semakin canggih, standar baru ataupun keinginan dari pihak owner yang melakukan perubahan dalam lingkup pekerjaannya. Kesuksesan suatu proyek sangat ditentukan oleh baiknya kerjasama antara owner dan penyedia jasa dengan menerapkan ketepatan teknis.

Rework adalah suatu pekerjaan ulang yang diakibatkan karena kesalahan-kesalahan dari suatu pelaksanaan proyek konstruksi.
Faktor-faktor apa saja yang menjadi penyebab terjadinya rework pada pekerjaan struktur saat pelaksanaan proyek konstruksi gedung di kota Padang?

- Faktor apa saja yang dominan menjadi penyebab rework pada pekerjaan struktur saat pelaksanaan proyek konstruksi gedung di kota Padang?

\section{Tujuan Penelitian}

- Untuk mengetahui faktor-faktor penyebab terjadinya rework pada pekerjaan struktur saat pelaksanaan proyek konstruksi gedung di kota Padang.

\section{Rumusan Masalah}




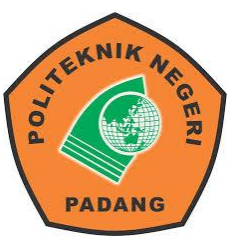

Available online at : http://ejournal2.pnp.ac.id/index.php/iirs/ $\underline{\text { Terakreditasi SINTAPeringkat } 5}$
- Untuk mengetahui faktor dominan apa saja yang menyebabkan terjadinya rework pada pekerjaan struktur saat pelaksanaan proyek konstruksi gedung di kota Padang.

- Untuk mengetahui seberapa besar faktor dominan dalam mempengaruhi rework pada pekerjaan struktur saat pelaksanaan proyek konstruksi gedung di kota Padang.

\section{TINJAUAN PUSTAKA}

\section{Defenisi Rework}

Rework dalam bahasa Indonesia diartikan sebagai pekerjaan ulang. International Automotive Task Force 16949 (IATF) menegaskan, rework adalah mengembalikan produk cacat ke spesifikasi semula, baik dengan proses yang sama ketika dibuat ataupun melaluai proses lain.

Defenisi rework menurut pandangan beberapa peneliti, antara lain :

- Josepson et al (2002) mendefenisikan rework sebagai mengerjakan sesuatu paling tidak satu kali lebih banyak, yang disebabkan oleh ketidakcocokan dengan permintaan.

- CIDA (Construction Industry Development Agency, 1995), rework adalah efek yang tidak perlu dari mengerjakan ulang suatu proses atau aktivitas yang diimplementasikan secara tidak tepat pada awalnya dan dapat ditimbulkan oleh kesalahan ataupun adanya variasi.

- Cll (Construction Industry Institute oleh pemiliknya, Cause and Effect of Field Rework Research Team 153, 2000), rework adalah melakukan pekerjaan di lapangan lebih dari sekali atau aktifitas yang memindahkan pekerjaan yang telah dilakukan sebelumnya sebagai bagian dari proyek.

- COAA (Construction Owner Association of Alberta, 2002) pekerjaan ulang adalah aktifitas di lapangan yang harus diselesaikan lebih dari satu kali di lapangan atau menghilangkan pekerjaan sebelumnya yang telah dilakukan dimana tidak ada permintaan perubahan dari pemilik proyek sebelum pekerjaan tersebut dikerjakan.

- Fayek et al (2002) mendefinisikan rework adalah aktifitas di lapangan lebih dari sekali ataupun aktivitas yang menghilangkan pekerjaan yang telah dilakukan sebelumnya sebagai bagian dari proyek diluar sumber daya, dimana tidak ada change order dan change of scope yang diidentifikasi.

\section{Faktor-faktor Penyebab Terjadinya Rework}

Menurut Winata dan Hendarlim (2005) penyebab-penyebab terjadinya re-work dikelompokkan menjadi tiga bagian yaitu:

- Faktor yang berkaitan dengan manajerial Faktor- faktor ini bisa disebabkan oleh semua pihak dikonstruksi, baik itu pemilik, konsultan manajemen konstruksi, konsultan pengawas, dan/atau kontraktor.

- Faktor yang berkaitan dengan sumber daya (resources)

Faktor sumber daya ini biasanya muncul pada fase konstruksi dan terjadi mengakibatkan adanya kesalahan pengerjaan di lapangan. Selengkapnya dijelas-kan dalam Gambar 2.1 


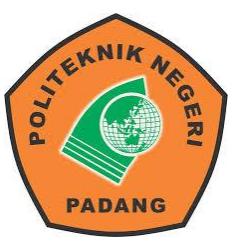

Available online at : http://ejournal2.pnp.ac.id/index.php/iirs/ $\underline{\text { Terakreditasi SINTAPeringkat } 5}$

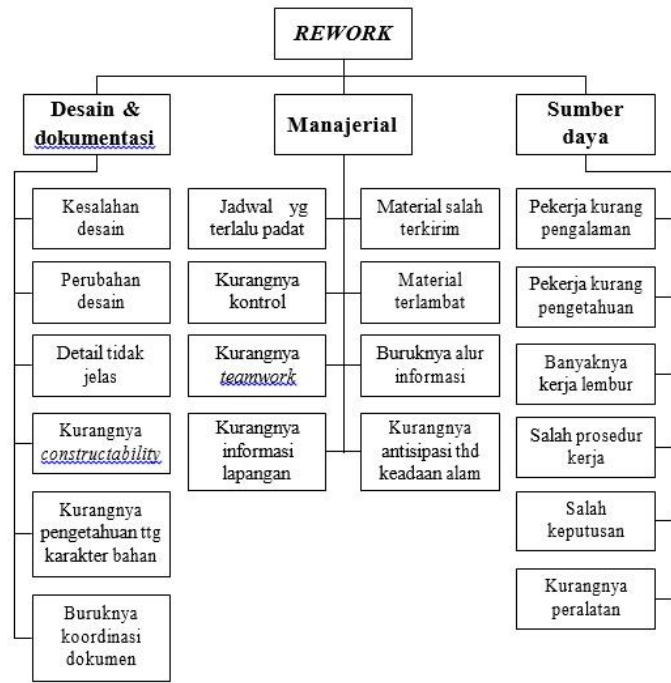

Gambar 2.1. Faktor-faktor penyebab rework Sumber: Andi, 2005

- Faktor metoda pelaksanaan konstruksi

Menurut Herdianto, Ardhan et al (2014) metoda pelaksanaan proyek merupakan salah satu faktor yang menjadi penyebab rework, metoda kerja yang tidak sesuai dengan kondisi lapangan, hingga penggunaan alat yang tidak sesuai dengan fungsinya.

\section{- Faktor material}

Menurut Irfan, Rahmatul et al (2012) faktor material adalah salah satu faktor yang menjadi penyebab terjadi rework. Tidak sesuainya mutu material yang terpasang di lapangan kerap menjadi rework.

- Faktor yang berhubungan dengan lingkungan proyek

Menurut Herdianto, Ardhan et al (2014) lingkungan proyek merupakan salah satu faktor yang menjadi penyebab rework, yaitu kondisi alam yang tidak sesuai dengan perkiraan, adanya gangguan dari lingkungan sekitar dan cuaca yang ekstrim.

Klasifikasi rework menurut Alwi, S (2002) yang dikutip oleh Erick (2014) penyebab terjadinya rework dikategorikan menjadi penyebab internal seperti kurangnya pengawasan, kurangnya tenaga ahli, gambar kerja yang kurang jelas sampai dengan minimnya peralatan kerja dan penyebab eksternal yakni perubahan gambar, buruknya desain atau terjadinya desain ulang, jeleknya kondisi lapangan kerja dan buruknya kualitas material yang digunakan.

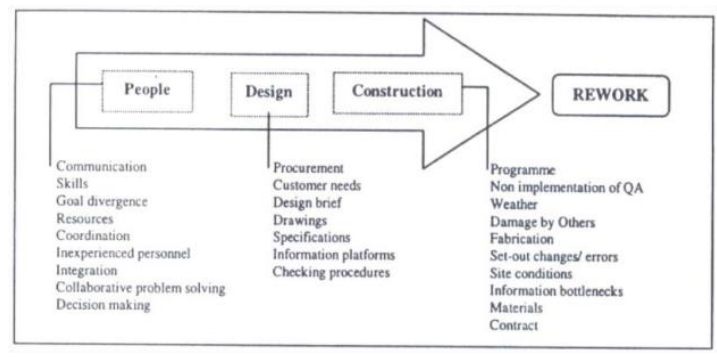

Gambar 2.2. Klasifikasi penyebab rework Sumber: Alwi, S. 2002

Pada penelitian ini, peneliti menetapkan 5 faktor yang diidentifikasi sebagai penyabab rework, lihat Tabel 2.1

\section{Dampak Rework}

Dampak adanya rework bagi perusahaan konstruksi adalah semakin besarnya biaya yang harus dikeluarkan dan waktu proses konstruksi menjadi semakin lama. Biaya rework adalah biaya yang dikeluarkan untuk mengerjakan ulang produk yang tidak lolos inspeksi. Semakin besar biaya rework maka total biaya yang harus dikeluarkan oleh perusahaan menjadi semakin 


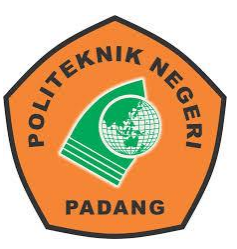

besar, sehingga profit perusahaan akan berkurang.

\section{METODOLOGI PENELITIAN}

Penelitian ini dilakukan terhadap kontrak-tor di kota Padang yang telah atau sedang

\section{Jurnal IImiah Rekayasa Sipil}

Available online at : http://ejournal2.pnp.ac.id/index.php/iirs/

\section{Terakreditasi SINTAPeringkat 5}

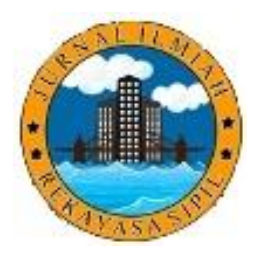

melaksanakan proyek konstruksi gedung dalam kurun waktu 10 tahun terakhir (20092019) yang tergabung dalam anggota GAPENSI (Gabungan Pelaksana Konstruksi Nasional Indonesia).

\section{Diagram Alir Penelitian}

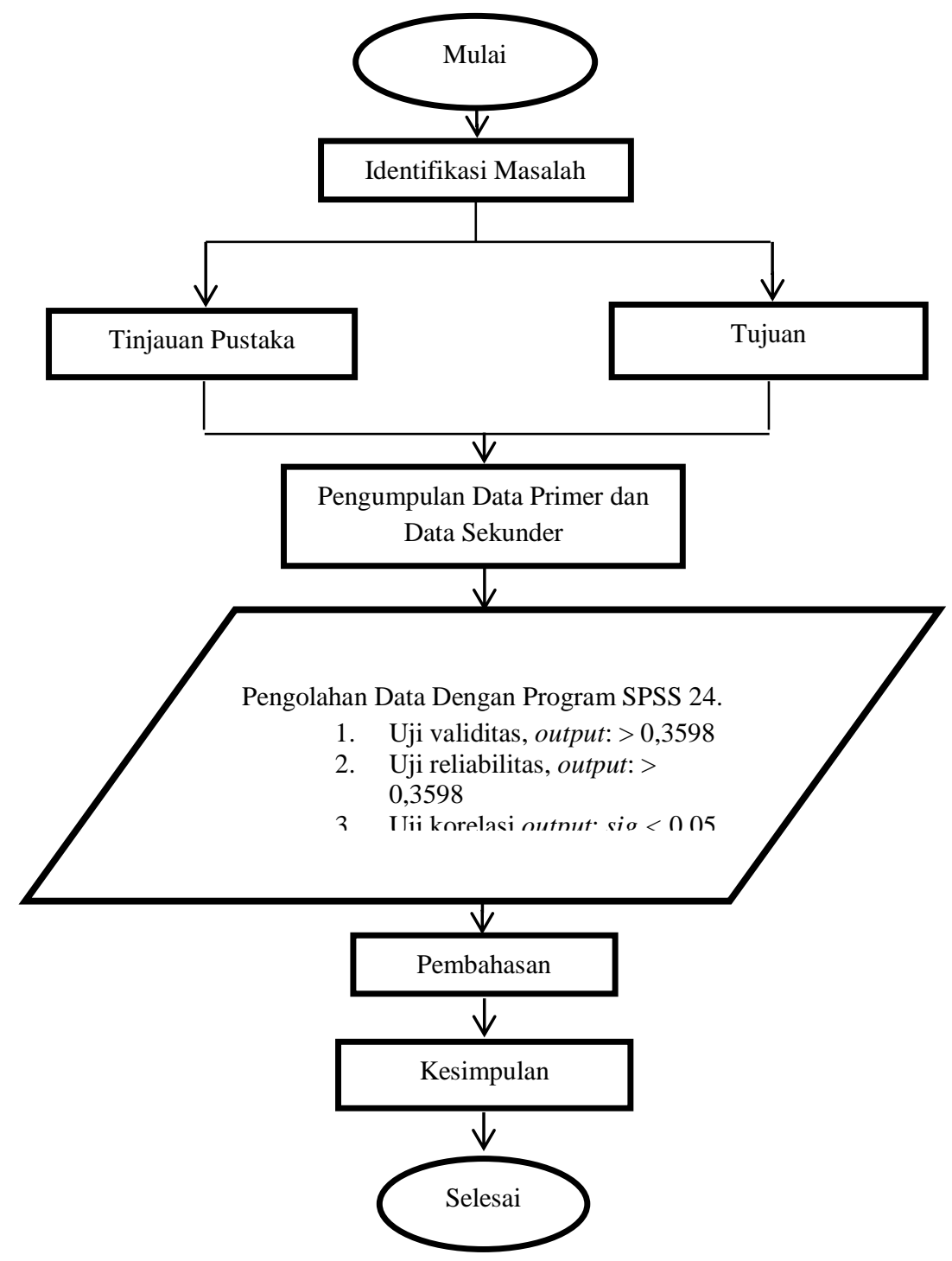

Gambar 3.1. Diagram alir penelitian

Sumber : Data primer, Desember 2019 


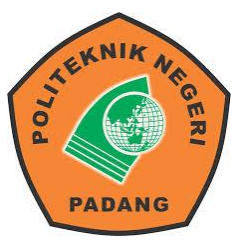

\section{Jurnal IImiah Rekayasa Sipil}

Available online at : http://ejournal2.pnp.ac.id/index.php/iirs/

Terakreditasi SINTAPeringkat 5

Tabel 2.1 Reliabel untuk nilai Cronbach's Alpha

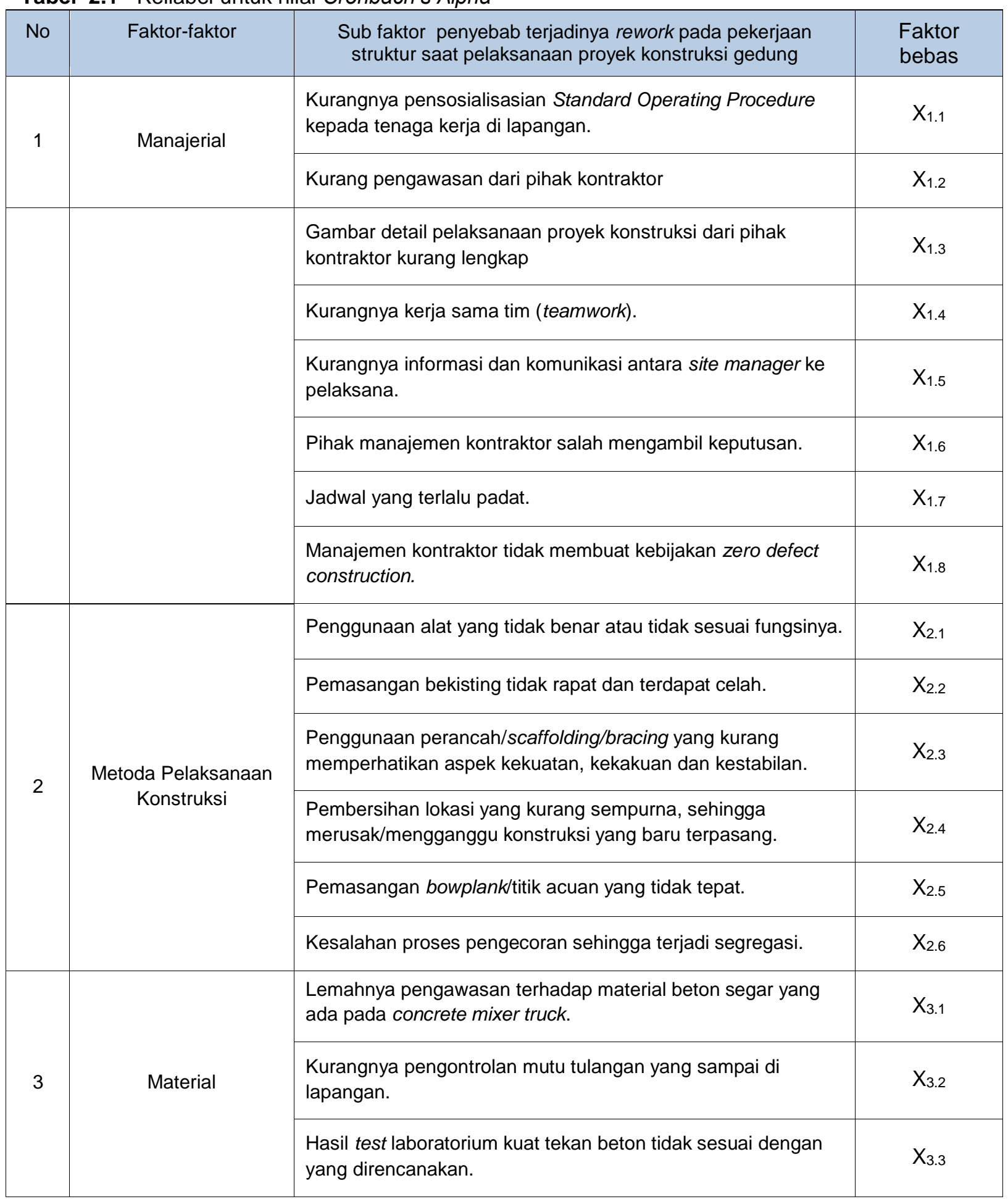




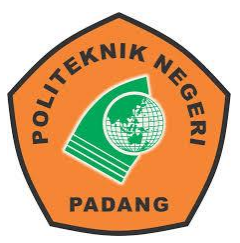

\section{Jurnal IImiah Rekayasa Sipil}

Available online at : http://ejournal2.pnp.ac.id/index.php/iirs/ Terakreditasi SINTAPeringkat 5

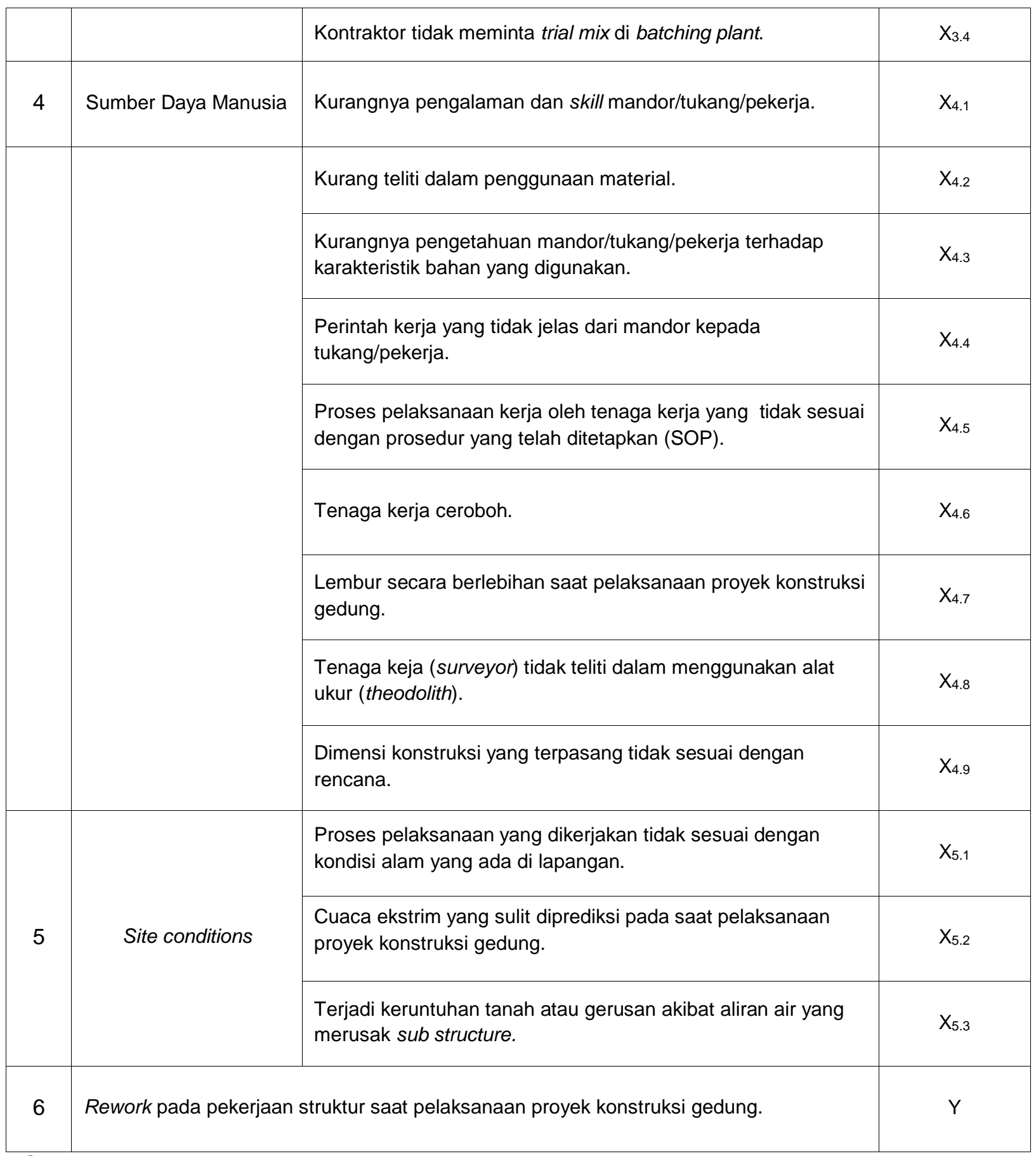

Sumber: Data Primer, Desember 2018

\section{Uji Validitas}

Validitas adalah pengujian untuk mengetahui sejauh mana ketepatan dan kecermatan suatu alat ukur dalam melakukan fungsi ukurnya. Pengujian validitas dilakukan dengan menggunakan program SPSS 24 . Uji validitas yang akan dibahas adalah validnya sebuah item pertanyaan dalam kuesioner. 


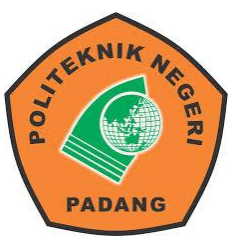

Available online at : http://ejournal2.pnp.ac.id/index.php/iirs/ $\underline{\text { Terakreditasi SINTAPeringkat } 5}$

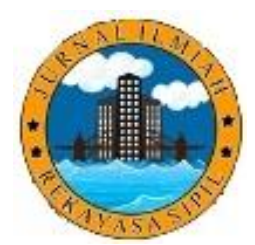

Pengujian validitas diproses dengan SPSS 24.00, yakni dengan mendeteksi nilai Correted Item Total Correlation hasil output SPSS 24.00. Jika nilai Corrected

Item Total Corelation yang diperoleh untuk setiap pernyataan lebih besar dari rabel (pada penelitian ini $r_{\text {tabel }}=0,3598$ ) maka data valid.

\section{Uji Reabilitas}

Pengujian reliabilitas adalah pengukuran yang dilakukan untuk tingkat keandalan data atau kekonsistenan dari data artinya kapan pun data disampaikan kepada pengisi maka jawaban dari mereka akan selalu sama. Uji reliabilitas dilakukan guna menentukan reliabilitas serangkaian item pertanyaan dalam kehandalannnya mengukur variable. Lihat Tabel 3.1.

Tabel 3.1 Reliabel untuk nilai Cronbach's Alpha

\begin{tabular}{|c|c|c|}
\hline No. & Nilai Alpha & Reliabel \\
\hline 1. & $0,00-0,20$ & Kurang Reliabel \\
\hline 2. & $0,21-0,40$ & Agak Reliabel \\
\hline 3. & $0,41-0,60$ & Cukup Reliabel \\
\hline 4. & $0,61-0,80$ & Reliabel \\
\hline 5. & $0,81-1$ & Sangat Reliabel \\
\hline
\end{tabular}

Sumber: Triton (2005) yang dikutip dari Palulun (2017)

\section{Uji Korelasi Pearson Product Moment}

Uji analisa korelasi Pearson Product Moment adalah salah satu dari beberapa jenis uji korelasi yang digunakan untuk mengetahui derajat keeratan hubungan 2 variabel yang berskala interval atau rasio, dimana dengan uji ini akan mengembalikan nilai koefisien korelasi yang nilainya antara -1, 0 dan 1 .
Tabel 3.2 Interpretasi nilai koefisien korelasi

\begin{tabular}{|c|c|}
\hline Interval Koefisien & Tingkat Hubungan \\
\hline $0.81-1.00$ & Korelasi Sempurna \\
\hline $0.61-0.80$ & Korelasi Kuat \\
\hline $0.41-0.60$ & Korelasi Sedang \\
\hline $0.21-0.4$ & Korelasi Lemah \\
\hline $0.00-0.20$ & Tidak Berkorelasi \\
\hline
\end{tabular}

Sumber : www.spssindonesia.com, Des 2018

\section{Analisa Deskriptif}

Menurut Moh. Nazir (Dalam Mandani, 2010), metode deskriptif adalah suatu metode dalam meneliti status sekelompok manusia, suatu obyek, suatu set kondisi, suatu sistem pemikiran ataupun suatu kelas peristiwa pada masa sekarang. Tujuan dari analisis deskripsi adalah membuat deskripsi gambaran yang sistematis, faktual dan akurat mengenai faktafakta yang diteliti di lapangan merupakan analisis yang digunakan untuk mengolah data yang diperoleh dalam bentuk angka kemudian dideskripsikan berdasarkan distribusi frekuensi, nilai rata-rata dan deviasi standar melalui perhitungan statistik.

\section{PEMBAHASAN}

\section{Deskripsi Responden}

Subjek penelitian atau responden adalah pihak-pihak yang dijadikan sebagai sampel dalam sebuah penelitian. Subjek penelitian juga membahas karakteristik subjek yang digunakan dalam penelitian, termasuk penjelasan mengenai populasi, sampel dan teknik sampling yang digunakan.

Responden dalam penelitian ini adalah 22 responden, dimana pada satu perusahaan terdapat 2 responden yaitu project manager 


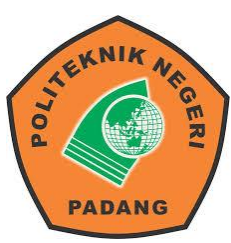

Available online at : http://ejournal2.pnp.ac.id/index.php/iirs/ $\underline{\text { Terakreditasi SINTAPeringkat } 5}$

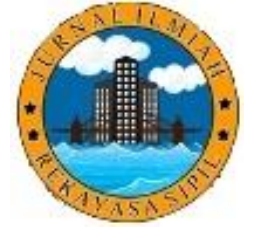

dan site manager dari pihak kontraktor gedung di kota Padang.

\section{Karakteristik Responden Berdasarkan} Pendidikan Terakhir

\section{PENDIDIKAN TERAKHIR}

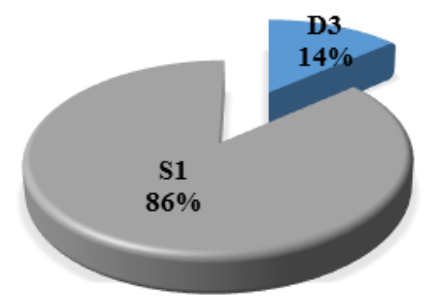

Gambar 4.1. Diagram Pendidikan Terakhir Responden

Sumber : Data primer, Februari 2019

Dari Gambar 4.1 dapat dilihat bahwa responden dengan pendidikan terakhir jenjang Strata Satu (S1) sebesar $86 \%$ dan pada jenjang Diploma Tiga (D3) sebesar 14\%. Grafik di atas menunjukkan hampir seluruh responden berlatar belakang pendidikan Strata Satu (S1), ini membuktikan bahwa di dalam dunia konstruksi banyak membutuhkan tenaga yang berpendidikan tinggi untuk mengimbangi pesatnya teknologi yang berkembang. Namun tidak menutup kemungkinan dengan yang memiliki latar belakang pendidikan Diploma Tiga (D3). Karena selain latar belakang pendidikan yang tinggi, kecakapan personal juga sangat dibutuhkan dalam bidang ini.

$\begin{array}{lll}\text { Karakteristik Responden } & \text { Berdasarkan } \\ \text { Pengalaman } & \text { Bekerja di } & \text { Perusahaan } \\ \text { Kontraktor } & & \end{array}$

\section{LAMA BEKERJA DI PERUSAHAAN KONTRAKTOR}

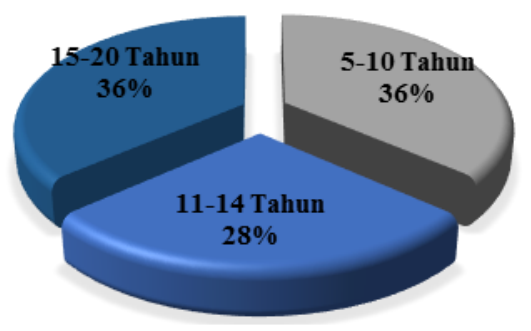

Gambar 4.2. Diagram lama responden bekerja di perusahaan kontraktor Sumber : Data primer, Februari 2019

Dari Gambar 4.2 dapat dilihat bahwa pengalaman responden bekerja di perusahaan kontraktor untuk semua jenis jabatan berbedabeda setiap responden. Untuk kelompok <5 tahun adalah sebanyak $0 \%$, kelompok 5-10 tahun adalah sebesar 36\%, kelompok 11-14 tahun adalah sebesar 28\% dan 15-20 tahun adalah $36 \%$ dan kelompok yang pengalamannya besar dari 20 tahun sebesar $0 \%$. Dapat dilihat bahwa semua responden yang telah masuk ke dalam dunia konstruksi umumnya telah memiliki pengalaman yang lebih dari 5 tahun diberbagai jabatan proyek. Ini tentu akan menjamin kualitas terhadap jawaban kuesioner yang peneliti ajukan kepada para responden, mengingat responden yang ditinjau oleh peneliti terlah memiliki pengalaman yang mumpuni dibidang jasa konstruksi, khususnya konstruksi gedung. Uji Validitas

Untuk hasil dari pengujian validitas atas data-data yang didapatkan pada penelitian ini dengan melakukan penyebaran kuesioner akan diuraikan pada Tabel 4.1. 


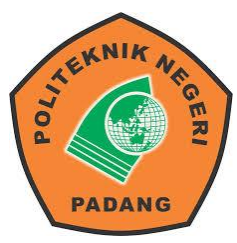

Available online at : http://ejournal2.pnp.ac.id/index.php/iirs/ $\underline{\text { Terakreditasi SINTAPeringkat } 5}$
Tabel 4.1 Interpretasi nilai koefisien korelasi

\begin{tabular}{|c|c|c|c|}
\hline $\begin{array}{c}\text { Sub } \\
\text { Faktor }\end{array}$ & $\mathbf{r}$ tabel & $\begin{array}{c}\mathbf{r} \\
\text { hitung }\end{array}$ & Keterangan \\
\hline X1.1 & .3598 & .545 & Valid \\
\hline X1.2 & .3598 & .466 & Valid \\
\hline X1.3 & .3598 & .725 & Valid \\
\hline X1.4 & .3598 & .403 & Valid \\
\hline X1.5 & .3598 & .636 & Valid \\
\hline X1.6 & .3598 & .865 & Valid \\
\hline X1.7 & .3598 & .822 & Valid \\
\hline X1.8 & .3598 & .696 & Valid \\
\hline X2.1 & .3598 & .790 & Valid \\
\hline X2.2 & .3598 & .373 & Valid \\
\hline X2.3 & .3598 & .778 & Valid \\
\hline X2.4 & .3598 & .286 & Tidak Valid \\
\hline X2.5 & .3598 & .458 & Valid \\
\hline X2.6 & .3598 & .797 & Valid \\
\hline X3.1 & .3598 & .484 & Valid \\
\hline X3.2 & .3598 & .555 & Valid \\
\hline X3.3 & .3598 & .456 & Valid \\
\hline X3.4 & .3598 & .539 & Valid \\
\hline X4.1 & .3598 & .866 & Valid \\
\hline X4.2 & .3598 & .410 & Valid \\
\hline X4.3 & .3598 & .866 & Valid \\
\hline X4.4 & .3598 & .678 & Valid \\
\hline X4.5 & .3598 & .760 & Valid \\
\hline X4.6 & .3598 & .578 & Valid \\
\hline X4.7 & .3598 & .361 & Valid \\
\hline X4.8 & .3598 & .636 & Valid \\
\hline X4.9 & .3598 & .374 & Valid \\
\hline X5.1 & .3598 & .851 & Valid \\
\hline X5.2 & .3598 & .447 & Valid \\
\hline X5.3 & .3598 & .538 & Valid \\
\hline Sumb & Data & .79649 \\
\hline
\end{tabular}

Sumber : Data primer, Februari 2019
Berdasarkan Tabel 4.1 dapat dilihat bahwa ada satu sub faktor (X2.4) yang memiliki nilai $r_{\text {hitung }}<r_{\text {tabel }}$ dengan nilai sebesar 0,286 . Ini menyatakan bahwa sub faktor tersebut tidak valid. Oleh sebab itu dapat dikatakan bahwa sub faktor tersebut tidak berpengaruh terhadap penyebab terjadinya rework. Selanjutnya untuk sub faktor yang dinyatakan tidak valid harus dieliminasi pada pengujian selanjutnya. Sedangkan untuk sub faktor lainnya memiliki nilai $r_{\text {hitung }}>r_{\text {tabel }}$ dapat dinyatakan bahwa sub faktor tersebut valid serta dapat disimpulkan bahwa untuk pertanyaan-pertanyaan tersebut sangat relevan dan sesuai dengan kondisi proyek yang dialami oleh responden.

\section{Uji Reabilitas}

Teknik uji reliabilitas yang dapat digunakan adalah teknik konsistensi internal dengan metoda stabilitas Cronbach's Alpha. Cronbach's Alpha diukur berdasarkan skala nilai Cronbach's Alpha 0 sampai dengan 1. Jika skala itu dikelompokkan ke dalam 5 kelas dengan range yang sama, maka ukuran kemantapan nilai Cronbach's Alpha dapat diinterprestasikan pada Tabel 3.1.

Untuk hasil dari pengujian reabilitas atas data-data yang didapatkan pada penelitian ini dengan melakukan penyebaran kuesioner akan diuraikan pada Tabel 4.2. 


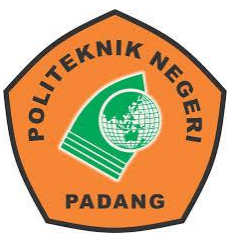

\section{Jurnal IImiah Rekayasa Sipil}

Available online at : http://ejournal2.pnp.ac.id/index.php/iirs/ Terakreditasi SINTAPeringkat 5

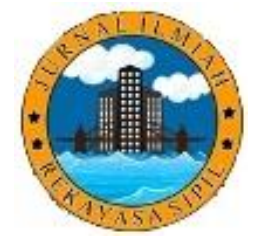

Tabel 4.2. Hasil uji reabilitas

\begin{tabular}{|l|c|c|c|}
\hline \multicolumn{1}{|c|}{ Faktor-faktor } & r table & r hitung & Keterangan \\
\hline Manajerial (X1) & .3598 & .869 & Sangat Reliabel \\
\hline Metoda pelaksanaan konstruksi (X2) & .3598 & .822 & Sangat Reliabel \\
\hline Material (X3) & .3598 & .713 & Reliabel \\
\hline Sumberdaya manusia (X4) & .3598 & .876 & Sangat Reliabel \\
\hline Site conditions (X5) & .3598 & .846 & Sangat Reliabel \\
\hline
\end{tabular}

Sumber : Data primer, Februari 2019

\section{Uji Korelasi Pearson Product Moment}

Uji analisa Pearson Product Moment adalah salah satu dari beberapa jenis uji korelasi yang digunakan untuk mengetahui derajat keeratan hubungan 2 faktor yang berskala interval atau rasio, dimana dengan uji ini akan mengembalikan nilai koefisien korelasi yang nilainya berkisar antara $-1,0$ dan 1. Lihat Tabel 4.3.

Tabel 4.3. Rekapitulasi hasil uji korelasi Pearson Product Moment

\begin{tabular}{|c|c|c|c|c|c|}
\hline No. & Faktor & $\begin{array}{l}\text { Sub } \\
\text { Faktor }\end{array}$ & Sig. (2-tailed) & $\begin{array}{l}\text { Nilai Koefisien } \\
\text { Korelasi }\end{array}$ & Tingkat Hubungan \\
\hline 1 & \multirow{8}{*}{$\mathrm{X} 1$} & $\mathrm{X} 1.1$ & 0.843 & 0.045 & Tidak Berkorelasi \\
\hline 2 & & $\mathrm{X} 1.2$ & 0.016 & 0.508 & Korelasi Kuat \\
\hline 3 & & $\mathrm{X} 1.3$ & 0.078 & 0.384 & Korelasi Lemah \\
\hline 4 & & $\mathrm{X} 1.4$ & 0.002 & 0.614 & Korelasi Kuat \\
\hline 5 & & $\mathrm{X} 1.5$ & 0.140 & 0.325 & Korelasi Lemah \\
\hline 6 & & $\mathrm{X} 1.6$ & 0.064 & 0.402 & Korelasi Sedang \\
\hline 7 & & $\mathrm{X} 1.7$ & 0.250 & 0.256 & Korelasi Lemah \\
\hline 8 & & $\mathrm{X} 1.8$ & 0.051 & 0.421 & Korelasi Sedang \\
\hline 9 & \multirow{5}{*}{$\mathrm{X} 2$} & $\mathrm{X} 2.1$ & 0.083 & 0.378 & Korelasi Lemah \\
\hline 10 & & $\mathrm{X} 2.2$ & 0.708 & 0.085 & Tidak Berkorelasi \\
\hline 11 & & $\mathrm{X} 2.3$ & 0.064 & 0.402 & Korelasi Sedang \\
\hline 13 & & $\mathrm{X} 2.5$ & 0.203 & -0.283 & Korelasi Lemah \\
\hline 14 & & $\mathrm{X} 2.6$ & 0.048 & 0.425 & Korelasi Sedang \\
\hline 15 & \multirow{2}{*}{$\mathrm{X} 3$} & $\mathrm{X} 3.1$ & 0.300 & 0.231 & Korelasi Lemah \\
\hline 16 & & $\mathrm{X} 3.2$ & 0.416 & 0.183 & Tidak Berkorelasi \\
\hline 17 & & $\mathrm{X} 3.3$ & 0.009 & 0.543 & Korelasi Kuat \\
\hline 18 & & X3.4 & 0.078 & 0.384 & Korelasi Lemah \\
\hline 19 & \multirow{5}{*}{$\mathrm{X} 4$} & $\times 4.1$ & 0.594 & -0.120 & Tidak Berkorelasi \\
\hline 20 & & $\mathrm{X} 4.2$ & 0.953 & -0.013 & Tidak Berkorelasi \\
\hline 21 & & $X 4.3$ & 0.594 & -0.120 & Tidak Berkorelasi \\
\hline 22 & & $X 4.4$ & 0.741 & -0.075 & Tidak Berkorelasi \\
\hline 23 & & $X 4.5$ & 1.000 & 0.000 & Tidak Berkorelasi \\
\hline 24 & \multirow{3}{*}{$\mathrm{X} 4$} & $X 4.6$ & 0.845 & 0.044 & Tidak Berkorelasi \\
\hline 25 & & $\times 4.7$ & 0.649 & -0.103 & Tidak Berkorelasi \\
\hline 26 & & $X 4.8$ & 0.394 & -0.191 & Tidak Berkorelasi \\
\hline
\end{tabular}




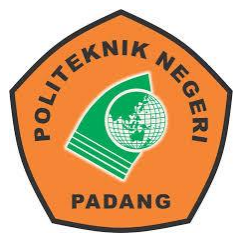

\section{Jurnal IImiah Rekayasa Sipil}

Available online at : http://ejournal2.pnp.ac.id/index.php/iirs/ Terakreditasi SINTAPeringkat 5

\begin{tabular}{|c|c|c|c|c|c|}
\hline 27 & & $\times 4.9$ & 0.750 & -0.072 & Tidak Berkorelasi \\
\hline 28 & \multirow{3}{*}{$\times 5$} & $\times 5.1$ & 0.018 & -0.500 & Korelasi Kuat \\
\hline 29 & & $\times 5.2$ & 0.203 & -0.283 & Korelasi Lemah \\
\hline 30 & & $\times 5.3$ & 0.182 & -0.295 & Korelasi Lemah \\
\hline
\end{tabular}

Sumber : Data primer, Februari 2019

Berdasarkan Tabel 4.3 rekapitulasi hasil pengujian korelasi di atas, terdapat terdapat beberapa sub faktor yang memiliki tingkat hubungan yang lemah bahkan ada yang tidak terdapat hubungan sama sekali terhadap rework pada pekerjaan struktur saat pelaksanaan proyek konstruksi gedung. Pada pengujian selanjutnya, data yang diuji adalah data yang memiliki tingkat hubungan sedang, kuat dan sempurna.

\section{Uji Analisa Deskriptif Berdasarkan Nilai} Mean

Skala penilaian yang digunakan peneliti untuk menyusun pertanyaan questionnaire nantinya adalah dengan skala Likert dimana responden diberi pilihan (option) yang kemudian tinggal memilih derajat keseringan/jarang atas pernyataan yang diajukan. (Sugiyono, 2012).

Adapun skala penilaian yang dimaksud adalah sebagai berikut:

$\begin{array}{lll}\text { Skor } 5 \text { = Sangat Sering } & (81 \%-100 \%) \\ \text { Skor } 4 \text { = Sering } & (61 \%-80 \%) & ) \\ \text { Skor } 3 \text { = Kadang-kadang } & (41 \%-60 \%) & ) \\ \text { Skor } 2 \text { = Jarang } & (21 \%-40 \% & ) \\ \text { Skor } 1 \text { = Sangat Jarang } & (00 \%-20 \%)\end{array}$

Tabel 4.4. Rekapitulasi hasil uji analisa deskriptif berdasarkan nilai mean

\begin{tabular}{|c|c|c|c||}
\hline \hline No & Sub faktor yang menjadi penyebab terjadinya rework & Mean & $\begin{array}{c}\text { Persentase } \\
(\%)\end{array}$ \\
\hline \hline 1 & $\begin{array}{c}\text { Kurang pengawasan dari pihak kontraktor sehingga spesifikasi } \\
\text { material yang terpasang pada pekerjaan struktur tidak sesuai } \\
\text { dengan spesifikasi teknis (X1.2). }\end{array}$ & 3.86 & 77.20 \\
\hline 2 & $\begin{array}{r}\text { Kurangnya kerja sama tim (teamwork) sehingga hasil konstruksi } \\
\text { tidak sesuai dengan kontrak (X1.4). }\end{array}$ & 4.32 & 77.20 \\
\hline 3 & $\begin{array}{c}\text { Kesalahan proses pengecoran sehingga terjadi segregasi (X2.6). } \\
\text { yang direncanakan (X3.3). }\end{array}$ & 3.86 & 75.40 \\
\hline 5 & $\begin{array}{r}\text { Hasil test laboratorium kuat tekan beton tidak sesuai dengan } \\
\text { alam yang ada di lapangan (X5.1). }\end{array}$ & 3.95 & 79.00 \\
\hline \hline
\end{tabular}

Sumber : Data primer, Februari 2019 


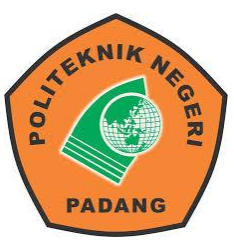

\section{Jurnal IImiah Rekayasa Sipil \\ Available online at : http://ejournal2.pnp.ac.id/index.php/iirs/ Terakreditasi SINTAPeringkat 5}

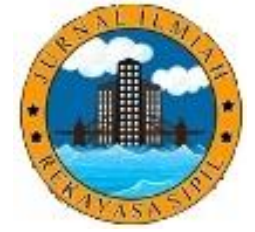

Berdasarkan Tabel 4.55 maka dapat diambil kesimpulan bahwa sub faktor yang paling dominan menjadi penyebab rework pada pekerjaan struktur saat pelaksanaan proyek konstruksi gedung di kota Padang adalah kurangnya kerja sama tim (teamwork) sehingga hasil konstruksi tidak sesuai dengan kontrak (X1.4) dengan nilai mean sebesar

4.32 dan persentase pemilihan sebesar $86.64 \%$.

\section{Pembahasan}

Penelitian ini dilakukan untuk mendapatkan jawaban dari pertanyaanpertanyaan penelitian yaitu: Pertama, Faktorfaktor apa saja yang menjadi penyebab terjadinya rework pada pekerjaan struktur saat pelaksanaan proyek konstruksi gedung di kota Padang?. Kedua, Faktor apa saja yang dominan menjadi penyebab rework pada pekerjaan struktur saat pelaksanaan proyek konstruksi gedung di kota Padang?

Sebelum melakukan penyebaran kuesioner kepada para responden penelitian, peneliti terlebih dahulu mengidentifikasikan faktor-faktor apa saja yang menjadi penyebab terjadinya rework pada proyek konstruksi gedung. Dalam mengidentifikasi faktor-faktor penyebab rework, peneliti mengambil dari studi literatur terhadap jurnal-jurnal terkait dengan penelitian yang dilakukan pada penelitian ini. Setelah dirasa cukup untuk pertanyaan pada kuesioner, selanjutnya peneliti melakukan penyebaran kuesioner kepada responden-responden yang memiliki kantor kontraktor di kota Padang. Setelah penyebaran kuesioner selesai dan data telah terkumpul, selanjutnya dilakukan pengolahan data dengan software SPSS 24.00 dengan kriteria uji data yaitu, uji validitas, uji reabilitas, uji korelasi Pearson Product Moment dan uji analisis deskriptif berdasarkan nilai mean.

Dari hasil pengujian validitas, terdapat satu sub faktor yang tidak valid, yaitu sub faktor (X2.4). Sehingga pada pengujian selanjutnya sub faktor tersebut harus dieliminasi dari daftar pertanyaan. Adapun sub faktor yang dimaksud adalah pembersihan lokasi yang kurang sempurna, sehingga merusak/mengganggu konstruksi yang baru terpasang. Sehingga pada pengujian reabilitas untuk faktor metoda pelaksanaan konstruksi, sub faktor (X2.4) sudah tidak di input dalam program SPSS 24.00.

Untuk pengujian analisis deskriptif berdasarkan nilai mean, data yang digunakan adalah data-data yang memiliki korelasi terhadap rework pada pekerjaan struktur saat pelaksanaan proyek konstruksi gedung. Dari hasil pengolahan data uji analisis deskriptif, nilai mean tertinggi untuk faktor manajerial yaitu sub faktor (X1.4) dengan nilai mean 4.32. Untuk faktor metoda pelaksanaan konstruksi nilai mean yang didapat adalah sebesar 3.86 untuk sub faktor (X2.6), dan untuk faktor material yaitu sub faktor (X3.3) dengan nilai mean 3.77, serta faktor terakhir yaitu faktor site conditions yaitu sub faktor (X5.1) dengan nilai mean yang diperoleh yaitu sebesar 3.95. Berdasarkan hasil analisa diatas dapat ditarik kesimpulan bahwa faktor yang dominan menjadi penyebab terjadinya rework adalah 


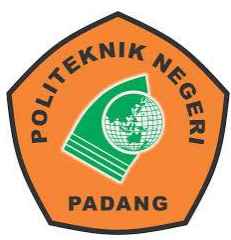

Available online at : http://ejournal2.pnp.ac.id/index.php/iirs/ Terakreditasi SINTAPeringkat 5 faktor manajerial dengan nilai mean terbesar diantara faktor-faktor yang lain dengan nilai sebesar 4.42. Manajerial yang baik dalam suatu proyek tentu akan sangat berdampak terhadap kelangsungan proyek konstruksi. Baiknya manajerial yang diterapkan dalam proyek akan meminimalisir terjadinya hal-hal yang tidak diinginkan.

\section{KESIMPULAN}

- 5 faktor penyebab terjadinya rework pada pekerjaan struktur saat pelaksanaan proyek konstruksi gedung di kota Padang antara lain: Faktor Manajerial, Faktor Metoda Pelaksanaan Konstruksi, Faktor Material, Faktor Sumberdaya Manusia dan Faktor Site Conditions.

- Berdasarkan hasil uji analisa deskriptif nilai mean terdapat 5 sub faktor dominan yang menjadi penyebab terjadinya rework pada pekerjaan struktur saat pelaksanaan proyek konstruksi gedung di kota Padang yaitu:

a. Sub faktor kurang pengawasan dari pihak kontraktor sehingga spesifikasi material yang terpasang pada pekerjaan struktur tidak sesuai dengan spesifikasi teknis (X1.2) dengan nilai mean 3.86 .

b. Sub faktor kurangnya kerja sama tim (teamwork) sehingga hasil konstruksi tidak sesuai dengan kontrak (X1.4) dengan nilai mean 4.32 .

c. Sub faktor kesalahan proses pengecoran sehingga terjadi segregasi (X2.6) dengan nilai mean 3.86 . d. Sub faktor hasil test laboratorium kuat tekan beton tidak sesuai dengan yang direncanakan (X3.3) dengan nilai mean 3.77 .

e. Sub faktor proses pelaksanaan yang dikerjakan tidak sesuai dengan kondisi alam yang ada di lapangan (X5.1) dengan nilai mean 3.95.

- Dari 5 sub faktor yang menyebabkan terjadinya rework pada pekerjaan struktur saat pelaksanaan proyek konstruksi gedung di kota Padang, terdapat sub faktor yang paling dominan menjadi penyebab terjadinya rework yaitu pada sub faktor kurangnya kerja sama tim (teamwork) sehingga hasil konstruksi tidak sesuai dengan kontrak (X1.4) dengan nilai mean 4.32 dan persentase sebesar $86.64 \%$, dapat disimpulkan bahwa besar pengaruh sub faktor tersebut terhadap terjadinya rework.

\section{DAFTAR PUSTAKA}

Ardhan, et al. 2015. Evaluasi Pengerjaan Ulang (Rework) Pada Proyek Konstruksi Gedung Di Semarang. Jurnal Karya Teknik Sipil, Vol. 4, No. 1. Universitas Diponegoro. Semarang.

Chundawan, et al. 2014. Model Sumber Dan Penyebab Rework Pada Tahapan Proyek Konstruksi. Universitas Kristen Petra. Surabaya.

Counstruction Industry Development Agency (CIDA). 1995. Measuring up or Muddling Tough. Best Practice in the Australian Non-Residentila Counstruction Industry. CIDA and Masters Builders Australia. Sydney Australia.

Fayek et al. 2002. Measuring and Classifying Counstruction Filed Rework. Apilot Study. 


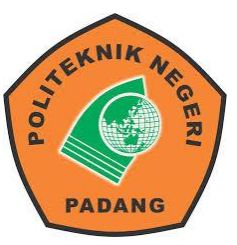

\section{Jurnal IImiah Rekayasa Sipil}

Available online at : http://ejournal2.pnp.ac.id/index.php/iirs/ Terakreditasi SINTAPeringkat 5

Irfan, et al. 2012. Faktor-Faktor Penyebab Pekerjaan Ulang (Rework) Pada Pembangunan Gedung Di Dinas Bina Marga Dan Cipta Karya Unsyiah. Jurnal Teknik Sipil, Vol. 1, No. 1. Universitas Syiah Kuala. Aceh.

Love, Peter. Influence of Project Type and Procurement Method on Rework Cost in Building Construction Projects, Journal of Construction Engineering Ana Management.

Napitupulu, et al. 2017. Identifikasi FaktorFaktor Penyebab Rework Pada Pekerjaan Konstruksi. Departemen Teknik Sipil. Universitas Sumatera Utara. Sumatera Utara.

Prianto, Kusnul. 2014. Analisa Faktor Penyebab Pekerjaan Ulang Pada Proyek Konstruksi Di Kota Malang. Jurnal IImuIImu Teknik, Vol. 10, No. 2. Universitas Wisnuwardhana. Malang.

Sartika, et al. 2013. Faktor-Faktor Penyebab Pekerjaan Ulang (Rework) Pada Proyek Gedung Di Kabupaten Rokan Hulu Berdasarkan Persepsi Kontraktor. Universitas Pasir Pengaraian. Riau.

Suparno. 2014. Penerapan Manajemen Mutu Dari Sumber Daya Manusia (People) Untuk Mengurangi Resiko Pekerjaan Ulang (Rework). Teknis, Vol. 9, No. 1. Politeknik Negeri Semarang. Semarang.

Sutrisna, et al. 2013. Analisis Rework Pada Proyek Konstruksi Gedung Di Kabupaten Bandung. Jurnal Spektra, Vol. 1, No. 2. Universitas Udayana. Bandung.

Winata, et al. 2005. Faktor- faktor Penyebab Rework pada Pekerjaan Konstruksi. Dimensi Teknik Sipil, Vol. 7, No. 1. Universitas Kristen Petra. Surabaya.

http://www.nusantaranews.net-/2017/08/menyigi-proyek-gedung-bertingkatsmp (diakses tanggal 11 November 2018) 